\title{
Review on Performance Measurement Systems
}

\author{
Shahryar Sorooshian* \\ Nor Filianie Aziz \\ Asraf Ahmad \\ Syafiah Norsyahira Jubidin \\ Nor Mahirah Mustapha \\ Faculty of Industrial Management, University Malaysia Pahang, Malaysia \\ *Corresponding author: sorooshian@gmail.com \\ Note: All authors have the same contribution to this work
}

Doi:10.5901/mjss.2016.v7n1p123

\section{Abstract}

Performance Measurement System (PMS) is an important system in the purpose of improving the organization performance. PMS create a very significant connection between organizations due to measurement in the organization system directly related to the organization strategy. A well develop and implementation of comprehensive PMS helps the organization to develop and improvise the business environment thus improve better decision making process. Therefore, there is multi comprehensive approaches of PMS has been applied in both quantitative and qualitative are significant to measure, predict and evaluate on current and future organization performance. The adoption of different models has had on various dimensions and measure give the difference result of organization performance. Therefore, this paper discuss on the different PMSs which have been developed to be used in companies. As one of the first comprehensive attempts in the performance management area, in this article almost all popular PMSs have been reviewed. Many of company managers have their own preferable performance management, but the least number of them is aware of different available PSMs. However, this paper found some of most favorable PMSs developed for adaptation by the organization recently; and concludes with a need for a comprehensive model.

Keywords: Performance Measurement System; Literature review; Organization Performance.

\section{Introduction}

Currently, performances of organizations are facing challenges due to rapid environmental changes (Yusra et al., 2015), which could cause a serious problem and even the eventual failure of the business (Sorooshian et al., 2011). This condition causes a number of needs associated with the performance measurement for organizations today. Based on Taticchi et al (2010), to improve business performance, measurement has been recognized as an important element. So, to maintain stability in the performance measurement, some aspect has been taken into account in this discussion. Through the selection of the method used to achieve successful and to provide maximum satisfaction to the performance of the company. In general, performance measurement is an evaluation of the organization and employees either financial or non-financial aspect. Performance measurement system (PMS) is an important thing to evaluate the organization performance. As stated by Sorooshian, Norzima, Yusof and Rosnah (2011), PMS has been and remains as a major challenge for scholars (Sorooshian et al. 2011). There is the need for more studies on performance (Sorooshian and Dodangeh, 2013). The main objective of this study is filling of the gap in literature review attempts in the area of PMSs. Therefore, the focus of this article is to systematically discuss current popular PMSs.

According to Michaela S. and Marketa S. (2012), performance measurement is a measure processes for the effectiveness and efficiency and productivity of past action. Performance measurement can be defined as an evaluation of how well organizations are managed and the value that is delivered to stakeholders and/or customers (Moullin, 2003). But from Wu (2009), the performance measurement definition is still debated. While PMS can be defined as a balancing and dynamic system that is able to supported the process of decision making from gathering, elaborating and analyzing of information (Neely, A; Adams C; and Kennerley M., 2002). As pointed out by Kaplan and Norton (1996), the balance 
concept can be referred to the market need are using the different measurement and perspectives that are working together to give an overview of the organization. Then dynamicity is indicated of developing a system that continuously monitors the external and internal aspect and objectives of the review and priorities (Taticchi et al. 2010). As we knows in the performance measurement area have any method and model design that is suitable for measures in organizations. There are many tools for reviewing and discussing in the PMS. It has also been able to create and developed a method based on the main characteristic of performance measurement. Minna S and Juhani U (2013), clarify that different approaches have shown a lot of interpretation of the PMS, and there is little dispute components and main characteristics. Meanwhile, the gap between questions what is want to be measured and what can be measure are main factors for performance measurement being a big challenge (Meyer 2002). When knows about the question of measuring the performance, the focusing both of the causes financial and non-financial, external and internal, and managerial aspects to discussing the method, approaches, and model design. So, the method will be identified based on the elements that are used.

The methodology of this article is qualitative research, and the used research method is literature review. This article reviews the available literature on PMSs to identify the most popular PMSs and to find a comprehensive PMS for practicing in organizations. The ten reviewed PMSs in this article are among top most popular PMSs. Balanced Scorecard, Performance Prism, Performance Measurement Matrix, Strategic Measurement and Reporting Technique, European Foundation for Quality Management and Theory of Constraints, Result and Determinant, Integrated PMS, Dynamic Multidimensional Performance Framework, Integrated Dynamic PMS, Holistic Performance Management, Medori and Steeple Framework and Qualitative Performance will be discuss in the review and application comparison of PMS.

\section{Literature Review}

There is a lot of Performance Measurement Systems (PMSs) model that are established in the business world. Meanwhile dissatisfaction with aspects of performance management in an organization has created numerous chances. This condition causes a number of problems associated with the performance measurement are used in organizations today. Based on Taticchi et al (2010), to improve business performance, measurement has been recognized as an important element. So, to maintain stability in the performance measurement, some aspect has been taken into account in this discussion. It is aim to find the best model of Performance Measurement System (PMS). Therefore, this discussion focuses on some of the approaches and model frameworks have been used for performance measurement areas based on characteristics that have been set. Through the selection of the method used to achieve successful and to provide strength and weaknesses about these models selected.

\subsection{Theory of Constraint (TOC)}

Theory of Constraints (TOC) established in 1980 by Goldratt to identify, analyze and eliminate the constraints identified that stop a firm's value adding process (Goldratt and Foz, 1986). An organization always has a constraint that retard the organization to achieve its goal (Jaideep M., Donal K., Raanan H., 1996). Therefore, Umble and Spoede (1991) come out that TOC is a whole management philosophy stress on constraint identification and management as the elements for focusing limited resources and time on area to achieve the whole goal of the organization.

TOC approach can be clearly understood to other some significant techniques as contrast. In Just-in-Time (JIT) and TQM are focused on lead-time, market share, eliminating waste, management commitment, statistical process control (SPC), throughput and simplification as the element to achieve sustainable improvement (Jaiddep M., et al., 1996). However, Jaiddep M., et al. (1996) claimed both excellence techniques apply any improvement will be practiced anywhere in the process to improve the whole organization performance. Jaiddep M., et al. (1996) stress in contrast the TOC is adapt the element of steel chain means the weakest link in the chain need to be identified in order to strengthen the chain overall. A chain here represents the multi-dimensions that involve in organization process. Thus, there is a interrelate chain in the organization to achieve a sustainable business performance (Jaiddep M., et al., 1996). Therefore, TOC provides the technique that focuses all local efforts on improving the related links to achieve bottom line improvement effectively.

TOC is a theory of "throughput orientation" together with three aspects: Mindset, Measures and Methodology (Boyd and Gupta, 2004). Mahesh C.G. and Lynn H.B. (2008) study to combine the TOC theory with four categories of operations decisions by Schroeder (2008) which are processes, quality, capacity and inventory in order to build the relationship between TOC and conventional Operation Management (OM) concept. 


\subsection{Performance Measurement Matrix (PMI)}

The PMI was first presented by Keegan et al. 1989. This performance measurement model will able to integrate the different dimensions of performance and employee generic terms. This matrix helps in defining the company strategic objectives and translates the objectives into performance measures using hierarchical and integrated approach that is simple and flexible. The external and internal perspectives combine with the cost and non-cost perspectives to form twoby-two approach.

The PMI support improvement collaboration performance by evaluating the collaboration itself and it also helps in better understanding in company strength and weakness. To implement this performance measurement model, factual and experience- based information is required for the successful operation.

According to Andersen et al. (2001), Fitzgerald in 1991 developed the advance system of the PMI called Result and Determinant which based totally on the key assumption. The key assumptions have two basic types of performance measure related to results and determinants of results. This Result and determinant shows that the results obtained are a function of past business performance with regard to specific determinants. Performance can be measured in terms of efficiency, effectiveness, collaboration, management skills and innovation aspects.

\subsection{European Foundation for Quality Management (EFQM)}

Dong Y.K, Vinod K. and Steven A.M (2010) claims that EFQM is a framework to evaluate the company for the European Quality Award (EQA) which aids to develop awareness of the significance of quality management. However, the EFQM Excellence Model can be used to achieve the sustained excellence not just in quality management, but in all aspects of performance (Frank M.G. and Robert G., 2010). Robert G. Hamlin and Frank M.G. (2010) added in their research on integrated quality management in tourist management claimed that this model to improve the performance of destination in Europe.

The development of EFQM Excellence Model is based on Total Quality Management (John D., 2008). Based on Dong Y.K et.al (2010), EFQM model is as the representative to improve the conventional principle of Total Quality Management (TQM). As a non-prescriptive framework, EFQM model comprising of nine criteria which divided by two areas, enablers and result to address the whole activities and interested parties and stakeholders in the organization, enabling the assessment of progress to achieve excellent performance (Alberto, Javier and Sergio, 2011). Other than that, the form one nine criteria are illustrating validated and leading-edge management practices (S. Wongrassamee et al., 2003). The model derived by 5 enablers which are people management, leadership, strategy and policy, processes and resources. In particular, there are 5 result covers of customer satisfaction, people satisfaction, business result and impact on society. Basically, what the company can manipulate is as an enabler and what the company will achieve as result (S. Wongrassamee et al., 2003).

Both areas enablers and result allocate balance weight (50-50). The percentage of every criterion represents the proportion of each criterion in the award assessment system of the EQA. It shows how each element is scored for importance. Lascelles and Peacock (1996) supported by S. Wongrassamee et al. (2003) stated that each of the Enabler is scored based on the two factors which are the degree of excellence of the approach and the degree of deployment of the approach. On top of that the Result also scored based on the two factors which first the degree of excellence of the result and the scope of the result. Stated by Joaqin and Micaela (2010) the innovation and the learning is to improve the enabler to achieve a sustain result.

The EFQM Excellence Model has been adopted in Europe as the frame of reference supporting the European Quality Award (Alberto et al. 2009; S. Wongrassamee et al., 2003). However, some European companies did not intend to win the award, the EFQM Excellence Model has been practiced to carry-out self-assessment as a benchmark of the organization position among competitors and lastly to achieve best performance business (S. Wongrassamee et al., 2003). Dong Y.K. et al. (2009) also support that EFQM model has been used in different ways, such as a tool of selfassessment, benchmarking, guide of improvement areas, basis for common vocabulary and a way of thinking and organization management structure. Therefore, The EFQM (1996) claimed that there are various approaches to carry out the self-assessment. Moreover, the chosen of self-assessment must involve the staff participation (Samuelsson and Nilsson, 2002).

In the other hand, there are limitations of self-assessment as a method of data collection because the selfassessment process must depend on good data collection (EFQM, 2003). Since different approaches to self-assessment are using different tools, the collection of data naturally less accurate and not comprehensive (John D., 2008). Thus, the multiple approaches to self-assessment relate to the second element impaction on perfect implementation which is 
EFQM maturity. Particularly, when the organization does not achieve the necessary maturity level, there will be waste resources to start the perfect self-assessment (Svensson and Klefsjö, 2006). If the organization does not put a vigorous effort on its way to achieve the maturity level, less complex designs of the questionnaire and matrix-chart approaches are recommended while the self-assessment by EFQM is highly suggested for mature organizations with a higher invested effort (Karapetrovic and Willborn, 2011). Martinez Lorento and Martinez Costa (2004) support that the adoption of EFQM as the step to be taken after the organization has implemented a quality management. Thus, the maturity level of the organization can be achieved by considering the availability of resources in terms of commitment, time, energy, information and finance that will affect the perfect for self-assessment (EFQM, 2003).

\subsection{Strategic Measurement and Reporting Technique (SMART) Performance Pyramid}

The Strategic Measurement and Reporting Technique performance pyramid was introduced by Cross and Lynch in 1991. This pyramid model builds of four levels that show the link between corporate strategy, strategic business unit and operation. First level is a definition of the overall corporate vision which then will be translated into individual business unit objectives. Second level shows the short-term targets of cash flow and profitability and long term goals of growth and market position. The third level is business operating systems which consist of customer satisfaction, flexibility and productivity. The last level, which is the fourth level is the business unit that consists four key performance measures (quality, delivery, cycle time and waste) which will then use in the department and work centers.

The SMART performance pyramid is a balanced model which measures stakeholder satisfaction such as customer satisfaction, quality and delivery. It also measures the operation activity for example productivity and lead time. The main strength of the SMART performance pyramid is links between corporate objectives with operational performance indicator (Kurien, \&Qureshi, 2011).

\subsection{Result and Determinants Framework (RDF)}

Results and Determinants Framework (RDF) also known as a Performance Measurement System for Service Industries was developed by Fitzgerald et al. (1991) that were focused on a service business. This framework followed three related elements such as model controlled in order to performance measurement determined; organizational analysis stages for measures of performance; and dimension to performance measurement. There are two basic types as related to RDF measurement dimension. The result is including competitive measure and financial measurement then determinants include quality, flexibility, resource utilization, and innovation. These elements become a very important dimension for the effective PMS. The strength of the RDF is that reaction with these factors (Ted and Carol, 2012).

RDF also acts as lagging and leading factor to measure the performance. Meanwhile, the result stands for lagging indicator and determinant become for leading indicators. Both of these factors are suitable for service performance measurement, but it just focuses on the financial and organizational strategy. According to Neetu, Sushil, and Mahim (2013) this framework failed to combine another non-financial performance measurement and also about stakeholders and behavioral aspects. Although it shows a strong specific measurement model for time-based competition that consider with any measures to follow the mission of time-based competition.

\subsection{Balanced Scorecard}

There are a variety of tools and techniques used in the performance measurement system. Among the tools and methods of model designs that succeed in the performance measurement system is balanced scorecard. Generally, the Balanced Scorecard (BSC) comes from United States in the late 1980s. The BSC was developed by Robert Kaplan and David Norton in 1992. BSC was developed to provide a better measurement of the organization. It also to produce a measurement model in the performance management to overcomes the weakness of traditional financial. According to Wu (2009), BSC does not only lead to a review of existing performance, but also find information related to the implementation of the organization in the future. In general, the BSC has been regarded as an important model in the company's performance management system because of the advantages inherent in the measurement system that focuses on the present and future generations.

From the previous research BSC can be defined is to know the measurement ways of activities carried out, the process occurs, and the output obtained in the success of an organization. Balanced scorecard also is a tool to describe, implement, and manage the strategy at all levels, such as top level until bottom level management in the organization. While, the concept of BCS shows that organization's too achieve of the balanced alignment must be focusing on four 
perspectives indicator such as generally supported achievement of the vision of the company (Meena C., 2009).

The BSC is combination financial and non-financial measure in a PMS. This combination is also known as a multidimensional model and measurement techniques procured from the vision and mission of the organization. Based on the performance measurement scope the BSC must be "balanced" to be successful in the future management. According to Michaela S. and Marketa S. (2012), the balanced is defined as two different aspects such as the short-term and long-term goals, required input and outputs, internal and external performance factors, and financial and non-financial indicators. The term of balanced must be seen through some of measurement angles with the assistance of the existing indicators. It is a tool that can measure the balanced between these two aspects and variables.

Mustafa C. and Damir F. (2008) stated that there are three stages in the development of BSC includes the BSC as a tool for performance measurement, systems for strategy management, and as a strategic system. This development also involved measurement of the four perspectives and ensure a balance indicator is achieved by evaluating two aspects of different dimensions. It also seems as a method of the cause-effect relationship between strategic vision and mission to achieve main aims. Then, the new development that is shown the BSC as a measurement system of developing strategic maps to provide strategic vision and mission and the innovation when it is implemented and development of the strategic management and supervise the strategic processes.

Compared with other models, BSC has been widely demonstrated success in the PMS. The concept of BSC also has certainly made its mark since a decade (Meena C., 2009). The BSC is a suitable model shows a balanced aspect in the PMS and this model has proven effectiveness of the company's performance measurement clearly by the researchers. According to previous studies the consumption of BSC is multiply used (Nopadol, 2011). There are researchers regarded that the BSC as an imperfect model for analyzing the performance of the company (Nopadol, 2011; Sorooshian, 2014). The causes maybe there are some shortcomings in the measurement of BSC model.

\subsection{Performance Prism}

The Performance Prism was introduced by Neely and Adam (2000). Generally, Performance Prism is a new development and conceptual system of PMS. It also considered as a second-generation after the old systems that contributes before like BSC. Then, the Performance Prism is a measurement tool that was developed by the strengths of existing measurement systems on shareholder value and shows some innovation. According to Milad A.S; Norlena $\mathrm{H}$; and Nor Hasni O. (2012), Performance Prism enclosed with the five branches of a prism such as stakeholder satisfaction, stakeholder contribution, strategies, processes, and capabilities (Wu, 2009).

The introduction of the Performance Prism that gives placed greater emphasis on all about stakeholder. It has been shown that the Performance Prism is very concerned about the want and needs of stakeholders. Michaela S. and Marketa S. (2012), the fulfillment of want and needs on the other side is expected by stakeholder to contribute to the organization. While, five of the perspectives are consist related questions based on the indicators. The Performance Prism framework was shown that stakeholder satisfactions have contributed to achieve the success in the organization (Frederico, 2009). Although, the stakeholders as supporting by items of an indicator processes, organization strategies, and the efficiencies to provide a better measurement in the companies. Strengths and weaknesses of the Performance Prism in the PMS are also a common concern because "the mark of Performance Prism is not truly proven as best measurement and it also works in practice" (Milad A.S. et al, 2012).

\subsection{Medori and Steeple Framework}

Medori and Steeple Framework develop both design and auditing PM system (P. Folan\& J. Browne, 2005). According to David Medori Derek Steeple, (2000) this framework develops by some criteria or requirements which are:

1. Measures procedure selection

2. Exercising the measures procedure

3. Audit capability

4. The measure is matched against a company's strategy

5. List of measuring the competitive priority

6. Periodic maintenance for future review

P. Folan et al., (2005) stated 5 advantages of implementing the framework which is help in developing a new performance measurement system, company able to audit it current measurement system, help in identifying obsolete measures, identify 'gaps' and prepare a guide to implement any selected measures

P. Folan et al., (2005) added that this framework is a system which converts the PM framework by measuring 
based on six competitive priorities which are cost, quality, flexibility, time, delivery and future growth. The completed framework consist of two documents which "Document A" is a workbook base in the six related areas and the other hand "Document B- Checklist" which contains 105 non-financial measures with a detail method of description and calculation. This framework of performance measurement system basically runs with six-stage plan outline (P. Folan et al., 2005; David et al., 2000).

1. Stage 1: Company success factor: The company performance measurement must be related to the company strategy and customer requirements.

2. Stage 2: Performance measurement grid (PMG): The six competitive priorities are aligned with the company strategic requirement

3. Stage 3: Selection of measure by referring "Document B-Spectrum/Checklist": The combination of grid from PMG and Document B will help the company to select the appropriate measure based on the six competitive priorities.

4. Stage 4: Auditing: The selection of measure in stage 3 will be compared with the current company performance measurement system. Three rules have to follow in audit process.

i. Current measures that tie with new measures are kept and consistently used

ii. Current measure that untie with new measures selected which bring bad consequences to the company will be scrapped

iii. New measures selected that untie with current measures are implemented. If there are no 'gaps' in the PM system which can bring a good measurement system to the company, the next stage is proceed (Dixon, Nanni and Vollman, 1990).

5. Stage 5: Implementation of measures: An eight steps to be followed in implementing new measures.

i. Title - clearly state the title based on the "Document B"

ii. Objective- the purpose of the measure link with the company's strategy

iii. Benchmark- due to a new measure, it should be compared with some reference to know either the company make an improvement or not

iv. Equation- how the measure is calculated

v. Frequency- how the company record the data and prepare the report

vi. Data source- where the data comes from either internal measurement or external measurement.

vii. Responsibility- who is the 'champion' in data collection and report preparation

viii. Improvement- it is based on either satisfactory performance or not.

6. Stage 6: Periodic maintenance: Particular performance measurement is available for a certain time and redundant at another part. This stage is significant to the company to revise the company strategy to enhance a better performance.

However, this framework is facing difficulties firstly in matching the six competitive priorities of PMG and a company strategy and secondly the "Document B" validity which it can be outdated (P. Faulan et al., 2005; David et al., 2000). David et al., (2000) is comparing BSC with Medori and Steeple framework due both are representative of the available PM. The study showed that Medori and Steeple framework is not dynamic because even the process is repeated, but the tools are static in nature. On the other hand, BSC is an ongoing process based on the non-prescriptive template to suit organization situation and environment.

\subsection{Dynamic Multidimensional Performance Framework (DMPF)}

Dynamic multi-dimensional performance framework is a model that provides guidance to management to develop useful success metrics regarding different situations and environment. This framework uses BSC and Success Dimensions model as a basis. It discussed about the limitation of the BSC and Success Dimensions models (Yadav and Sagar, 2013).

The five dimensions of DMPF are financial, market, process, people and the future. Financial perspective involves measures such as sales and profits or return on investment. While market perspective shows the relationship between customers and an organization and process perspective shows the organizational efficiency and important view because successful companies often focused on process improvement. From people perspective, this model focuses on the critical role of stakeholders, while for future perspective, it is crucial to prepare a measurement for the future are clearly expressed of foresight (Maltz et al., 2003). 


\subsection{Holistic Performance Management Framework (HPFM)}

According Bjørn Andersen BjørnarHenriksenWencheAarseth, (2006) believed that holistic position helps the company to consider the internal and external challenges. HPFM covers multiple connections of tools and concepts within the organization into a framework. It means that each element in the company designed to interact each other as a whole in the company process. Thus, in HPFM there are certain element play significant role in the framework while it also can be these elements are not relevant in some cases. However, the company cannot leave the design of each particular element and the entire framework must be clearly understood and designed to support each other.

Bjørn Andersen BjørnarHenriksenWencheAarseth (2006) explains figure 1 as stakeholder understanding and strategic planning are parts to elaborate the stakeholders' requirement and expectation. In strategic planning should consider the external stakeholder environment, internal resources and capabilities. Follow with the market research and segmentation which cover as sub-activities of strategic planning. The company should undertake the customer satisfaction which related to a relation customer approach where both product and service company have to develop a good relationship with the customer. Move to the internal perspective which is developing the business process. The time must be fully utilized and the company should develop, and create value to avoid any waste time and recourses and the same time cannot maximize the customer and organization needs.

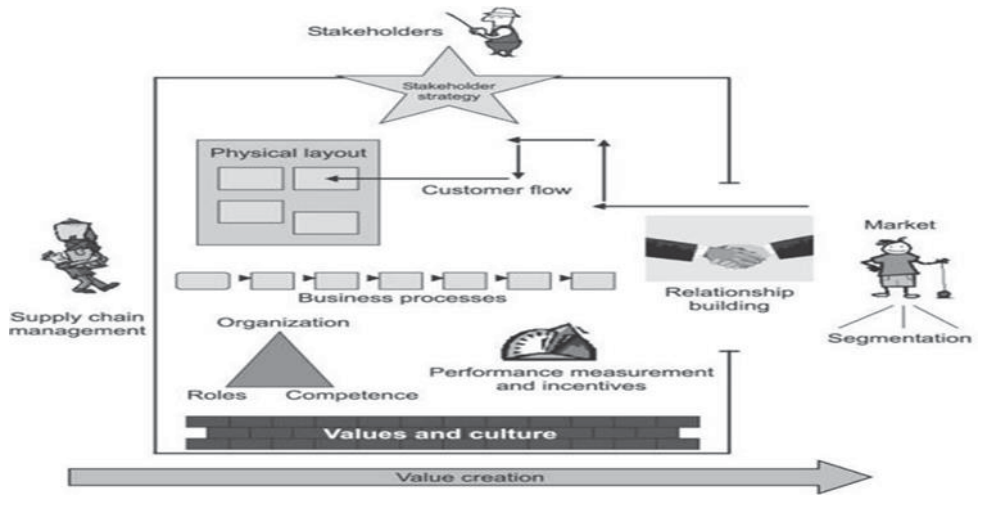

Figure 1. A Generic Performance Management Framework (Bjørn Andersen BjørnarHenriksenWencheAarseth, 2006)

Some innovation has been created due to McCormack (2001) stated company based on business process is a familiar approach. Thus, the business process should create simplicity, clear interface, avoid duplication and rework. The business process connected with the physical layout and facility design which it helps the business process to run effectively. In terms of physical infrastructure competency, roles and capacity of the organization must be clearly matched to each other. The role must be defined across the business process, the available recourses need in every part need to be determined and stated the type of competence. On the other hand, the core value of the company is based on company values and culture. A good values must be translated into the action follows the strategic goals and the company business process. Parts which relate to company values are incentives and performance management. Performance measurement, management is based on the employee behavior. Well employee behavior environments effect a good performance management. In terms of incentives, according to Kemmerer and Thiagarajan (1992), stated that incentives can influence people to act in certain ways which can motivate an employee to show a good performance on their task. Last but not least, leadership skill and management is the significant factors to bring the company successful.

However, the framework is inspired by the case company and the element in the HPFM is a natural place in the business performance management, although it is not exhaustive (Bjørn Andersen BjørnarHenriksenWencheAarseth, 2006). Bjørn Andersen BjørnarHenriksenWencheAarseth (2006) stated again that the element in the framework is flexible to the position and the background of the reader. 


\section{Conclusion}

This paper discussed some Performance Measurement Systems. The Performance Measurement System (PMS) which is designed to evaluate and measure the level of performance exhibited by a company. It aims to achieve maximum satisfaction level in the company's performance. However, the suitability of PMS should be viewed in detail to ensure every stage measurement can be identified and analyzed in the overall business environment. Hence, in this context PMS should be discussed in more detail the aspects of criteria, technique, tool, method, and model design used for measuring the success performance in each organization. Furthermore, fifteen existing models were selected to identify a lot of criterion that have in the PMS model approach. There is a lot of argument to compare the all performance measurement models, but most of them preferred Balance Scorecard (BSC) which introduce in 1992 which focused to achieve the strategic goals. Performance prism on the other hand is the newest model that has been introduced in 2001. This model constructed based on the BSC but focus more on the stakeholder. EFQM has no focus or priorities in the models which more suitable for benchmarking (Striteska, M. and Spickova, M. 2012). Theory of Constraint (TOC) is far from being the complete performance system, hence this model is least popular performance measurement. Compare PMI to BSC, performance matrix does not as packaged as the BSC. This shows the weakness of PMI. The SMART performance pyramid does not explicitly integrates the concept of continues improvement, hence does not as good as BSC.

The use of Result and Determinant Framework (RDF) see quite suitable for practical drawbacks, but this model only focused on the services sector only. In this situation BSC is still considered an acceptable model for efficient performance measurement in organizations, though some researchers disagree with its comprehensiveness. However, there is one model that is developed on the strength and weaknesses of the two original models of BSC and Success Dimension Model. The model known as Dynamic Multidimensional Performance Framework (DMPF) but this model makes it difficult reaction because there are imperfections that are sustainable. Although there is a high strength against BSC privileges, but Holistic Performance Measurement Framework (HPMF) is the closest competitor to show that there are advantages in line with the BSC but it is a new model and still less proven efficacy comparison. In general, there are some pro and cons for all developed PMSs; and refer to the reviewed literature, this article concludes with an alarm on lack of a comprehensive PMS model.

\section{References}

Alberto Bayo-Moriones, Javier Merino-Díaz-de-Cerio, Sergio Antonio Escamilla-de-León and Rejina Mary Selvam (2011), The impact of ISO 9000 and EFQM on the use of flexible work practices International Journal of Production Economics, 130(1), 33-42.

Andersen, H; Cobbold, L; and Lawrie, G (2001) Balanced Scorecard implementation in SMEs: reflection in literature and practice. 2GC Conference Paper, 1-12.

Angel R. Martínez-Lorente, Micaela Martínez-Costa, (2004) "ISO 9000 and TQM: substitutes or complementaries?: An empirical study in industrial companies", International Journal of Quality \& Reliability Management, 21 (3),260 - 276.

BjørnAndersenBjørnarHenriksenWencheAarseth, (2006). Holistic performance management: an integrated framework. International Journal of Productivity and Performance Management,55(1),61 - 78.

Boyd, L.H. and Gupta, M. C. (2004) Constraints management: what is the theory? International Journal of Operations \& Production Management, 24(4), 350-371.

Chavan, Meena (2009), The balanced scorecard: A new challenge, Journal of Management Development, 28(5), 393-406.

David MedoriDerek Steeple, (2000).A framework for auditing and enhancing performance measurement systems. International Journal of Operations \& Production Management, 20(5), $520-533$.

Doung Young Kim, Vinod Kumar, Steven A.Murphy (2010), European Foundation for Quality Management Business Excellence Model, International Journal of Quality and Reliability Management; 27(6):684-701.

EFQM, 2003. Assessing Excellence-A Practical Guide for Self Assessment. EFQM, Brussels.

Folan, P. and Browne, J. (2005) "A review of performance measurement: Towards performance management". Computers in industry. Vol. 56 pp. 663- 680 .

Frederico and Francisco, G. (2009), The measurement of organizational performance with a focus on stakeholder: A performance prism approach. 011-0471. 1-17.

Goldratt, E. M. and Fox, R.E., (1986) The Race North River Press, Croton-on-Hudson, New York, NY,1986

Goldratt, E. M. Computerized a shop floor scheduling. International Journal of Production Research, 26(3), 429-442.

Jaideep Motwani, Donald Klein, Raanan Harowitz, (1996). The theory of constraints in services. Managing Service Quality, 6 (1), $53-56$.

Joaquín Gómez Gómez · Micaela Martínez Costa - Angel R. Martínez Lorente. 2010,An in-depth review of the internal relationships of the EFQM model, Total Quality Management and Business Excellence Journal

John, D. (2008). Integration: is it the key to effective implementation of the EFQM Excellence Model? International Journal of Quality \& Reliability Management, 25(4), 383-399. 
Kaplan, R. S. \& Norton, D. P. (1992). The Balanced Scorecard: Translating Strategy into Action, Boston. Ma: Harvard Business School Press.

Kaplan, R.S. \& Norton, D.P. (1996a). Using the Balanced Scorecardad a strategic system. Harvard Business Review, January-February, $71-9$.

Kaplan, R.S. \& Norton, D.P. (1996b). The Balanced Scorecardad- Translating Strategy into action. Harvard Business Review, JanuaryFebruary, 71-9.

Karapetrovic, S. and Willborn, W. (2001), "Audit and self-assessment in quality management: comparison and compatibility", Managerial Auditing Journal, 16(6), 366-77.

Keegan, D.P, Eiler, R.G and Jones C.R. (1989) "Are your performance measures obsolete?" Management Accounting. 70 (12) , 45.

Kurien. G. P, Qureshi. M. N. (2011). Study of performance measurement practices in supply chain management. International Journal of Business, Management and Social Sciences, 2(4),19-34

L Fitzgerald (with T JBrignall, R Johnston and R Silvestro), Product Costing in Service Organizations, Management Accounting Research, ISSN 1044-5005, volume 2, number 4, pp 227־-248, 1991.

Lascelles, D.And Peacock, R. (1996).Quality in Action: Self Assement for Business Excellence, Berkshire, McGraww-Hill, UK.

Lynch, R. L. \& Cross, K. F. (1991), Measure Up! Yardsticks for Continuous Improvement, Basilblackwell, Oxford.

Magnus Svensson, Bengt Klefsjö, (2006) "TQM-based self-assessment in the education sector: Experiences from a Swedish upper secondary school project", Quality Assurance in Education, 14 (4),299 - 323

Mahesh C. Gupta \& Lynn H.Boyd, (2008). Theory of constraints: a theory for operations management. International Journal of Operation \& Production Management, 28 (10), 991-1012.

Maltz A.C, Shenhar A.J and Reilly R.R. (2003). Beyond the balance scorecard: refining the search for organizational success measures. Long Rang Planning, 36, 187-204.

Medori, D. and Steeple, D.S. (2000) "A framework for auditing and enhancing performance measurement systems". International Journal of Operations and Production Management. 20 (5), 520-533.

Meyer, M. W. (2002), Rethinking performance measurement: Beyond the balanced scorecard, in Cambridge University Press, 81-113.

Michaela Striteska and Marketa Spickova (2012) ,Review and Comparison of Performance Measurement Systems, Journal of Organizational Management Studies, Vol 2012.

Minna Saunila, Juhani Ukko, (2013) "Facilitating innovation capability through performance measurement: A study of Finnish SMEs", Management Research Review, 36 (10), 991 - 1010.

Moullin, M. (2003), 'defining performance measurement,' in perspectives on performance, 2(2):3

Mustafa Cengic, \& Damir Fazlic, BALANCED SCORECARD vs. PERFORMANCE PRISM. 12th International Research/Expert Conference "Trends in the Development of Machinery and Associated Technology" TMT 2008, Istanbul, Turkey, 26-30 August, 2008

Neely, A. \& Bourne, M. (2000). Why measurement initiatives fail? Measuring Business Excellence. 4(4). 3-6.

Neely, A., Adams, C., \& Kennerley, M. (2002), The performance prism: The scorecard for measuring and managing business success. Cranfield School of Management, 377, 1-13.

Neetu Yadav, Sushil and Mahim Sagar, DMS, IIT Delhi, ( 2013), -Performance measurement and management frameworks - Research trends of the last two decadesil, Business Process Management Journal, 19(6).

Robert G. Hamlin, Margaret Reidy and Jim Stewart (2010), Effecting Management Culture Change through Research-Based Management Development: A British Case Study Management Development Forum, 2(1), 99.

Rodney McAdam, Daniel McCormack, (2001) "Integrating business processes for global alignment and supply chain management", Business Process Management Journal, 7(2), pp.113 - 130.

Rompho, N. (2011), Why the balanced scorecard fails in SMEs: A case study. International Journal of Business and Management, 6(11), 39-46.

S.Wongrassamee, P.D., G., \& J.E. L., S. (2003). Performance measurement tools: the Balanced Scorecard and the EFQM Excellence Model. Measuring Business Excellence,7(1), 14-29.

Salem, M. A., Hasnan, N., \& Osman, N.H. (2012), Balanced scorecard: Weaknesses, strenghts, and its ability as performance management system versus other performance management system. Journal of Environment and Earth Science, Vol 2, No.9, 110.

Samuelsson, P., Nilsson, L-E., 2002. Self-assessment practices in large organizations. Experiences from using the EFQM excellence model. International Journal of Quality \& Reliability Management 19 (1), 10-23.

Schroeder, R., 2008. Operations management. New York: McGraw-Hill.

Sorooshian, S. (2014) Study on Unbalanceness of the Balanced Scorecard, Applied Mathematical Sciences, 8 (84), 4163-4169.

Sorooshian, S. Dodangeh, J. (2013). Modeling On Performance Drivers Of Project Management, Advances in Environmental Biology, 7(13), 3890-3894.

Sorooshian,S., Norzima Z., Yusof I., (2011) Descriptive Comparison of SME Performance Between Iran and UK, World Applied Sciences Journal, 15 (2), 239-243.

Sorooshian,S., Norzima Z., Yusof I., Rosnah Y., (2011), Relationship Between Drivers of Performance in Smaller Firms, Middle-East Journal of Scientific Research, 9 (4), 452-455.

Striteska, M., and Spickova, M. (2012). Review and comparison of performance measurement systems, Journal of Organizational Management Studies, 2012(2012), 1-12. 
Taticchi, P., Tonelli, F., \& Cagnozzo, L. (2010), Performance measurement and management: A literature review and a research agenda. Measuring Business Excellence, 14( 1), 4-18.

The European Foundation for Quality Management (EFQM) (1996).Self-Assessment 1996 Guidelines, EFQM, Brussels, Belgium.

Umble, M. and Srikanth, M. (1991) Synchronous Management: Profit Based Manufacturing for the 21stCentury,Vols I and II, Spectrum, Guilford, CT.

Umble, M., Umble, E. and Murkami, S. (2006). Implementing theory of constraints in a traditional Japanese manufacturing environment: The case of Hitachi tool engineering. IJPR,44(10), 15 May, 1863-80.

Watts, T. \& McNair-Connolly, C. J. (2012). New performance measurement and management control systems. Journal of Applied Accounting Research, 13 (3), 226-241.

Wu, D. (2009), Measuring performance in small and medium enterprises in the information \& communication technology industries. A Thesis Submitted in Fulfillment of the Requirements for the Degree of Doctorate of Philosophy, 1-209.

Yadav, N., Sagar, M..(2013). Performance measurement and management frameworks. Business Process Management Journal, 19(6), $947-971$.

Yusra, Y. L., Noor, A.B.A., Sorooshian, S., (2015). How are the Performance of Small Businesses Influenced by HRM Practices and Governmental Support?. Mediterranean Journal of Social Sciences, 6(1), 97-108. 